\title{
The changing mass of glaciers on the Tibetan Plateau, 2002-2016, using time-variable gravity from the GRACE satellite mission
}

https://doi.org/10.1515/jogs-2018-0010

Received April 6, 2018; accepted June 27, 2018

\begin{abstract}
The Tibetan Plateau is the largest region of high elevation in the world. The source of water for a number of important rivers, the Himalayan region is vital to the billions of inhabitants of the Asian continent. Over the last fifty years, the climate in the region has warmed more rapidly than anywhere else at the same latitude. Causes and effects, and the geographical details of these alarming warming trends are as yet not fully known. One way of assessing the effects of climate change in this area is to measure the change in glacier volume in the region, but estimates made on the basis of different techniques have not been conclusive to date, and remain difficult to reconcile. We examine the temporal behavior of the mass flux integrated over four distinct groupings of Tibetan glaciers using satellite gravimetry from the Gravity Recovery and Climate Experiment (GRACE). We use a technique known as spatio-spectral localization using spherical Slepian functions to convert global spherical harmonic expansions of the time-dependent geopotential into monthly estimates of mass changes over the Tibetan Plateau. Subsequent reductions are aimed at interpreting this mass change as due to gains or losses in ice mass. We find that (ice) mass has been decreasing on the Tibetan Plateau between 2002 and 2016 but with significant spatial variability throughout the region. Specifically, in the regions of Himalaya, Pamir, Qilian, and Tien Shan, glaciers have been losing ice mass at a rate of $-11 \pm 3,-1 \pm 2,+8 \pm 2$, and $-6 \pm 1 \mathrm{Gt} / \mathrm{yr}$, respectively, over the last decade.
\end{abstract}

Keywords: glacier mass loss, gravimetry, localization, Tibetan Plateau

\footnotetext{
Alyson K. Beveridge: Princeton University, Department of Geosciences, Princeton, NJ 08544, U.S.A.

*Corresponding Author: Christopher Harig: University of Arizona, Department of Geosciences, Tucson, AZ 85721, U.S.A., E-mail: charig@email.arizona.edu

Frederik J. Simons: Princeton University, Department of Geosciences, Princeton, NJ 08544, U.S.A.
}

\section{Introduction}

The Tibetan Plateau has been dubbed the Third Pole [1]. The largest high-elevation area in the world, covering an area of $2.5 \times 10^{6} \mathrm{~km}^{2}$, it is the region in the world with the most ice mass after the North and South Poles. The region has experienced significant warming over the past 50 years of $1.8^{\circ} \mathrm{C}$ [2]. This warming is greater than any other region of the world at the same latitude [3]. Over forty climate models agree that the area will continue warming over the next century, with predicted mean annual temperature increases ranging from $3.9-6.0^{\circ} \mathrm{C}$ by 2100 [4]. Regional minimum daily temperature has also increased at a rate double that of the daily maximum temperature increase $\left(0.41^{\circ} \mathrm{C} /\right.$ decade compared to $0.18^{\circ} \mathrm{C} /$ decade $)$ [5]. This asymmetric warming may lead to a more pronounced effect in colder regions such as the Tibetan Plateau. [6] estimated that regions at higher altitudes such as the Tibetan Plateau may warm faster than areas of low altitude. The causes and effects of this warming are not fully known, particularly on the local level [7].

Earth's cryosphere is affected by an increasing mean annual global temperature. Understanding the change in ice mass on the Tibetan Plateau in particular is essential for many reasons. Glaciers in the Tibetan Plateau are an important store of the Earth's freshwater. Glaciers and ice caps contain approximately $70 \%$ of the Earth's freshwater [8]. [9] estimated that, between 2003 and 2009, glacier mass wastage contributed $0.71 \pm 0.08 \mathrm{~mm}$ of sea-level equivalent per year which was $29 \pm 13 \%$ of observed sealevel rise. [10] found that for sea-level rise not attributed to thermal expansion, about $60 \%$ was attributed to melting of glaciers and ice caps rather than melting of the Greenland and Antarctica ice sheets. [10] estimated that accelerated glacier melting may cause 0.1 to $0.25 \mathrm{~m}$ of sea-level rise by 2100 . These studies suggest that the contributions to sea-level rise by glaciers on the Tibetan Plateau is certainly far from negligible.

In addition to affecting global sea-level rise, changes in mass of glaciers on the Tibetan Plateau have local 
implications on human health and survival [11]. Unlike Antarctica and Greenland, the glaciers of high mountain Asia play an important role in global water security. Nearly one quarter of the world's population depends on rivers fed partially from Tibetan Plateau, and these rivers run through some of the world's most densely populated and rapidly developing countries including China and India [12]. Water from these glaciers is used by hundreds of millions of people for industry, agriculture, power generation and drinking water. Glacial runoff from the western Himalaya on the Tibetan Plateau contributes $70 \%$ of the summer river flows of the Ganges and Indus rivers.

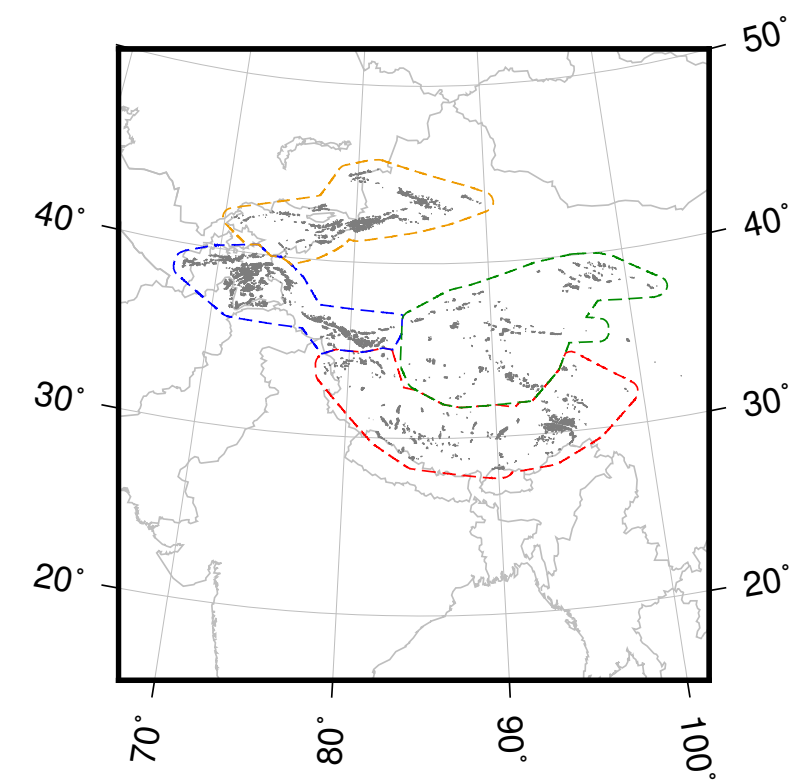

Figure 1: Regions of interest used in this study chosen based on areas used by [13]. Four different regions of interest: Tien Shan, outlined in yellow, Qilian outlined in green, Pamir outlined in blue, and Himalaya outlined in red. The glaciers, outlined in dark grey, represent the largest 10,000 by area glacial stock as measured by the Randolph Glacier Inventory [14]. Country political boundaries are shown in light grey.

As glaciers on the Tibetan Plateau are important water sources for surrounding drainage basins they are often considered the "Asian water towers" [15]. The effect of dwindling glaciers on these different basins is not thoroughly understood. A decrease in glacial runoff to these basins in the future, exacerbated by river seasonality, poses a serious threat to food and water security for nearly a fifth of the world's population. A dearth of knowledge on glacier and melt water interaction leaves a highly populated portion of the Earth potentially underprepared for water scarcity [16].
The seasonality of water availability, large populations, and the potential for political tension in the area make predicting the impacts of climate change a very pressing issue. No scientific consensus has been reached on the expected behavior of this area [17]. The region is very heterogeneous, hence small-scale sampling does not easily provide an accurate picture of the overall behavior [18]. Furthermore, ground-truthing of models is limited. Between 2000 and 2007 no major studies were published on the changes of ice mass in this region, until the assessments by the Intergovernmental Panel on Climate Change brought mass wasting of Himalayan glaciers again to the foreground.

Surface mass balance (SMB) of glaciers is determined by measuring net accumulation and ablation rates at the surface of the glacier, in the field, using a simple measuring stick or via GPS. These are compared with predictions from weather models for the region, ground-truthed by weather stations. GPS is furthermore used to measure rates of crustal uplift that can be associated with ice mass loss based on the vertical displacement of crust near glaciers [19]. Hence, GPS can provide a secondary measurement of the response to the change, rather than be a measurement of the change itself. Glacial thickness can be measured seismologically, by ice-penetrating radar, or by drilling [20]. However even the best local measurements do not offer a complete picture of glacial change over a large and possibly heterogeneous area. Moreover, SMB studies do not account for dynamic losses (due to flow) or basal melting [21].

In recent studies in the Himalaya, satellite-based measurements have been favored over SMB modeling. There are many ways to estimate the change in ice mass over a region from a satellite. Passive imagery measures change in surface area and albedo, but does not account for changes in ice thickness or density. Active laser and radar altimetry can measure the change in elevation of a glacier but cannot account for changes in density. The Geoscience Laser Altimeter System on the ICESat satellite has been used in many studies including [22]. Altimetry cannot directly measure the change in mass of glaciers as it measures only the change in relative altitude. Glacial models and estimates of glacial density need to be applied to the estimated change in volume in order to interpret the measurements in terms of the change in mass.

[23] compared surface mass balance and gravimetric techniques for measuring changes in acceleration of ice mass loss in Antarctica and Greenland and found the measurements fell within the same confidence intervals. However, for the Tibetan Plateau, measurements of change in ice mass using satellite gravimetry data have varied from 
4 to $61 \mathrm{Gt} / \mathrm{yr}[13,24]$. Part of the variation can be explained by the difference in techniques used to "localize" satellite gravimetry measurements, which include their expansion on grids, via point masses, using radial basis functions, mascons, or wavelets. [25] measured the changes in ice mass of the Greenland ice sheet with high spatiotemporal resolution using a robust optimized method that relies on spherical Slepian functions [26]. The same method was employed by [27] for the Antarctic region, and we will use their method in this study also. Using Slepian basis localization of satellite gravimetry we will measure the change and rate of change of ice mass on the Tibetan Plateau over the last twelve years.

Figure 1 shows the region of interest for this study as well as the glaciers present in the area according to the Randolph Glacier Inventory [14] and defined in [13].

\section{Data \& Methods}

We use data from the Gravity Recovery and Climate Experiment (GRACE), a mission launched in 2002 to deliver time-dependent measurements of the Earth's gravity field [28]. The GRACE satellites measure the Earth's gravity field via the geopotential difference between the leading and the trailing satellite. Over denser or more "massive" parts of the planet, the satellites will be pulled in a tighter orbit than when they are flying over less dense portions. Data from the GRACE missions provide high spatial and temporal resolution for the Earth's gravity field. Global trends that are visible in GRACE data and are changes in surface density which can include monsoons, droughts, current changes in ice mass and Glacial Isostatic Adjustment (GIA) from the previous deglaciation [29]. The GRACE mission data centers have returned monthly averages for the Earth's gravity for each of the past 150 months or so. The specific data set used in this study is the Release 05 Level 02 product processed by the Center for Space Research in Austin, Texas [30].

GRACE mission data are routinely delivered as a set of spherical harmonic coefficients which evenly parameterize the surface of the globe [27]. Spherical harmonics comprise a set of functions and their expansions coefficients by which to describe a field, such as the Earth's gravitational potential. The spherical harmonic coefficients are weights attached to the basis functions, generally available as monthly varying solutions, complete up to a maximum spherical harmonic degree or bandwidth $L=60$. When processing GRACE data, degree-one coefficients were replaced by the values determined by [31], and degree-two- zero coefficients were replaced by the values from satellite laser ranging [32].

A spherical harmonic of degree $l$ and order $m$, is a function of colatitude $\theta$, and longitude $\varphi$. With $l=0, \ldots, \infty$ and $m=-l, \ldots, l$ the $Y_{l m}(\theta, \varphi)$ form a complete orthonormal basis for all square-integrable functions $s$ that live on the surface of the unit sphere $\Omega$. Any bandlimited spherical function $f$ can be expressed as a finite sum of spherical harmonics,

$$
f(\theta, \varphi)=\sum_{l=0}^{L} \sum_{m=-l}^{l} f_{l m} Y_{l m}(\theta, \varphi),
$$

where $f_{l m}$ are the weights associated with the spherical harmonics $Y_{l m}$ and the bandwidth $L$ is the maximum spherical harmonic degree.

The set of spherical harmonics from the GRACE mission describe the gravity field of the entire Earth. For the typical GRACE bandwidth of $L=60$ (which is commensurate with the altitude of the satellites, about $400 \mathrm{~km}$ ) there, thus are 3721 degrees of freedom. However, in order to examine a specific subsection of the Earth it is not necessary to use all $(L+1)^{2}$ of them. The approximate number of pertinent functions, the effective size of the space of geopotential solutions is an "area-bandwidth product", a quantity termed the Shannon number,

$$
K=(L+1)^{2} \frac{A}{4 \pi},
$$

where $A / 4 / \pi$ is the fractional area of the region of interest on the unit sphere.

A Slepian function at the bandwidth $L$, and for a certain region $R$ is a bandlimited spherical harmonic expansion

$$
g_{\alpha}(\theta, \varphi)=\sum_{l=0}^{L} \sum_{m=-l}^{l} g_{\alpha l m} Y_{l m}(\theta, \varphi) .
$$

The expansion coefficients $g_{\alpha l m}$ are the eigenvectors of a matrix,

$$
\sum_{l^{\prime}} \sum_{m^{\prime}} D_{l m, l^{\prime} m^{\prime}} g_{\alpha l^{\prime} m^{\prime}}=\lambda_{\alpha} g_{\alpha l m},
$$

whose elements are

$$
D_{l m, l^{\prime} m^{\prime}}=\int_{R} Y_{l m}(\theta, \varphi) Y_{l^{\prime} m^{\prime}}(\theta, \varphi) d \Omega .
$$

Equation (5) presents the main computational burden in the determination of the Slepian functions for arbitrary regions $R$, although recent work has reduced this burden considerably [33].

Formally, the Slepian functions are eigenfunctions of an "area-bandwidth limiting operator", and the associated eigenvalues $\lambda_{\alpha}$ measure their "utility" in terms of 

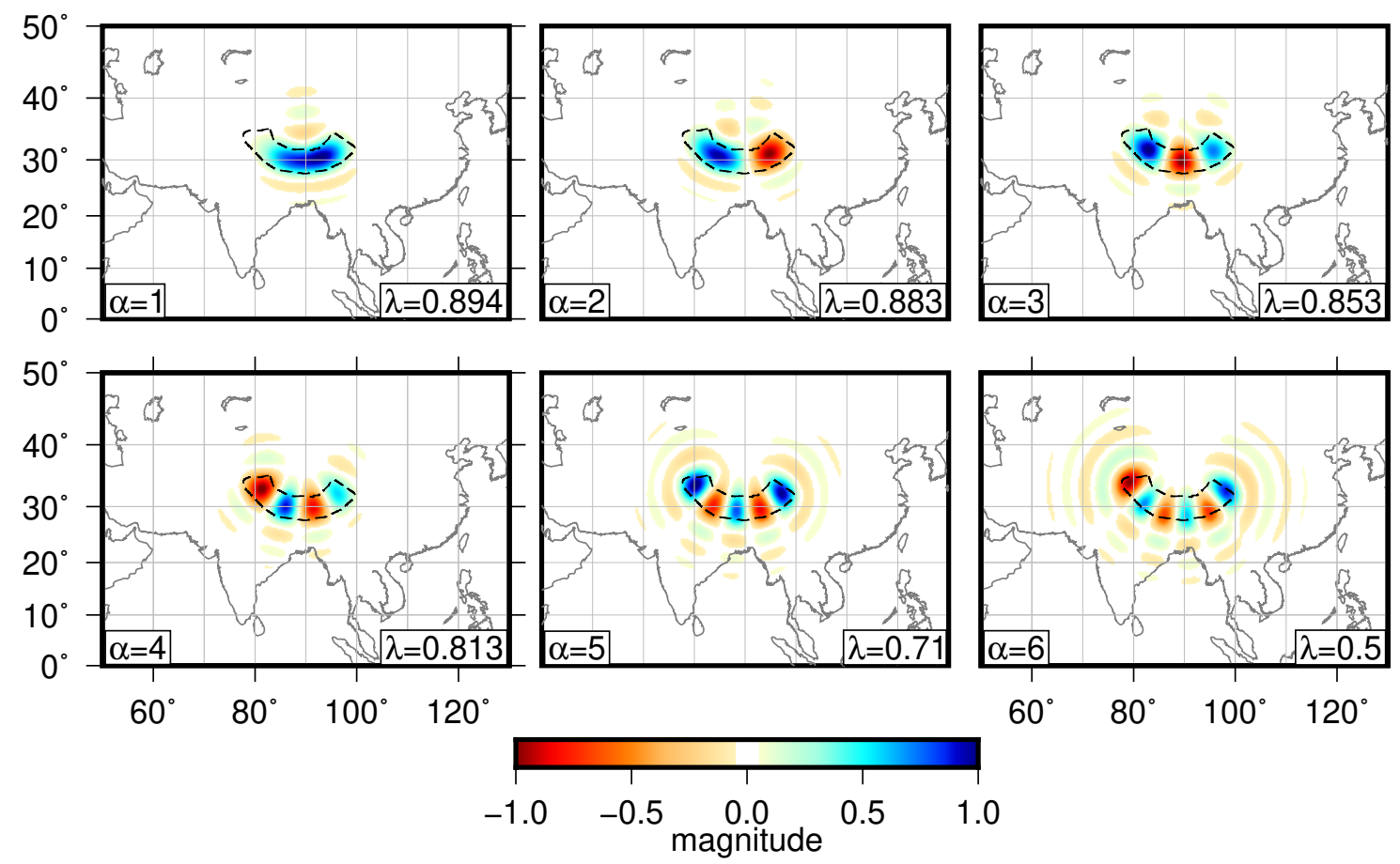

Figure 2: Well-concentrated $L=60$ Slepian functions, localized for the Himalayan region in central Asia. The region of concentration is outlined in a black dashed line. Coastlines are shown in light grey. $\alpha$ denotes the rank of the eigenfunction. The parameter $\lambda$ is the corresponding eigenvalue for each function indicating the amount of concentration. Magnitude values whose absolute values are smaller than 0.01 are left white.

their relative areal concentration:

$$
\frac{\int_{R} g_{\alpha}^{2}(\theta, \varphi) d \Omega}{\int_{\Omega} g_{\alpha}^{2}(\theta, \varphi) d \Omega}=\lambda_{\alpha} .
$$

In other words, $\lambda_{\alpha}$ is defined as the energy of the function $g_{\alpha}$ as measured over the region $R$ as a fraction of all of its energy over the entire sphere $\Omega$. The Shannon number $K$ equals the sum of all eigenvalues, and given the typically stair-step nature of the eigenvalue spectrum (with eigenvalues that are either very near unity or very near zero), it is also roughly the number of "useful" functions that suffices to approximately expand a bandlimited signal $L$ within the region $R$ of interest.

The Slepian function set constitutes on orthonormal basis for the entire sphere $\Omega$, and forms an approximate basis for functions that are concentrated over the region of interest $R$, which entails

$$
\begin{aligned}
f(\theta, \varphi) & =\sum_{\alpha=1}^{(L+1)^{2}} f_{\alpha} g_{\alpha}(\theta, \varphi), \quad \operatorname{for}(\theta, \varphi) \in \Omega, \\
& \approx \sum_{\alpha=1}^{K} f_{\alpha} g_{\alpha}(\theta, \varphi), \quad \text { for }(\theta, \varphi) \in R .
\end{aligned}
$$

Hence, the problem of "spatiospectral localization" of the global gravity geopotential, expressed in spherical harmonics $Y_{l m}$, into a new expansion valid over the region of interest, $R$, at the same resolution provided by the bandwidth $L$, amounts to finding the appropriate Slepian field expansion coefficients $f_{\alpha}$.

Equation (3) shows how the Slepian functions are linear transforms of spherical harmonics, from the properties of the matrix in Eq. (5), which is symmetric and positivedefinite, it now follows that the transformation of the basis coefficients $f_{l m}, l=0, \ldots, L, m=-l, \ldots, l$, to the localized set $f_{\alpha}, \alpha=1, \ldots,(L+1)^{2}$ is simply accomplished by

$$
f_{\alpha}=\sum_{l=0}^{L} \sum_{m=-l}^{l} g_{\alpha l m} f_{l m} .
$$

This gives us the transformed coefficients, $f_{\alpha}$, approximately $K$ of which will be required to provide good coverage over the region $R$.

In the construction of the appropriate Slepian functions, we thus have only a few available parameters to tune. These "knobs" are the bandwidth $L$, the geographical description of the region of interest $R$ and the precise number of functions required to provide a faithful representation of the unknown geopotential. The latter number depends on the signal-to-noise levels of the original 

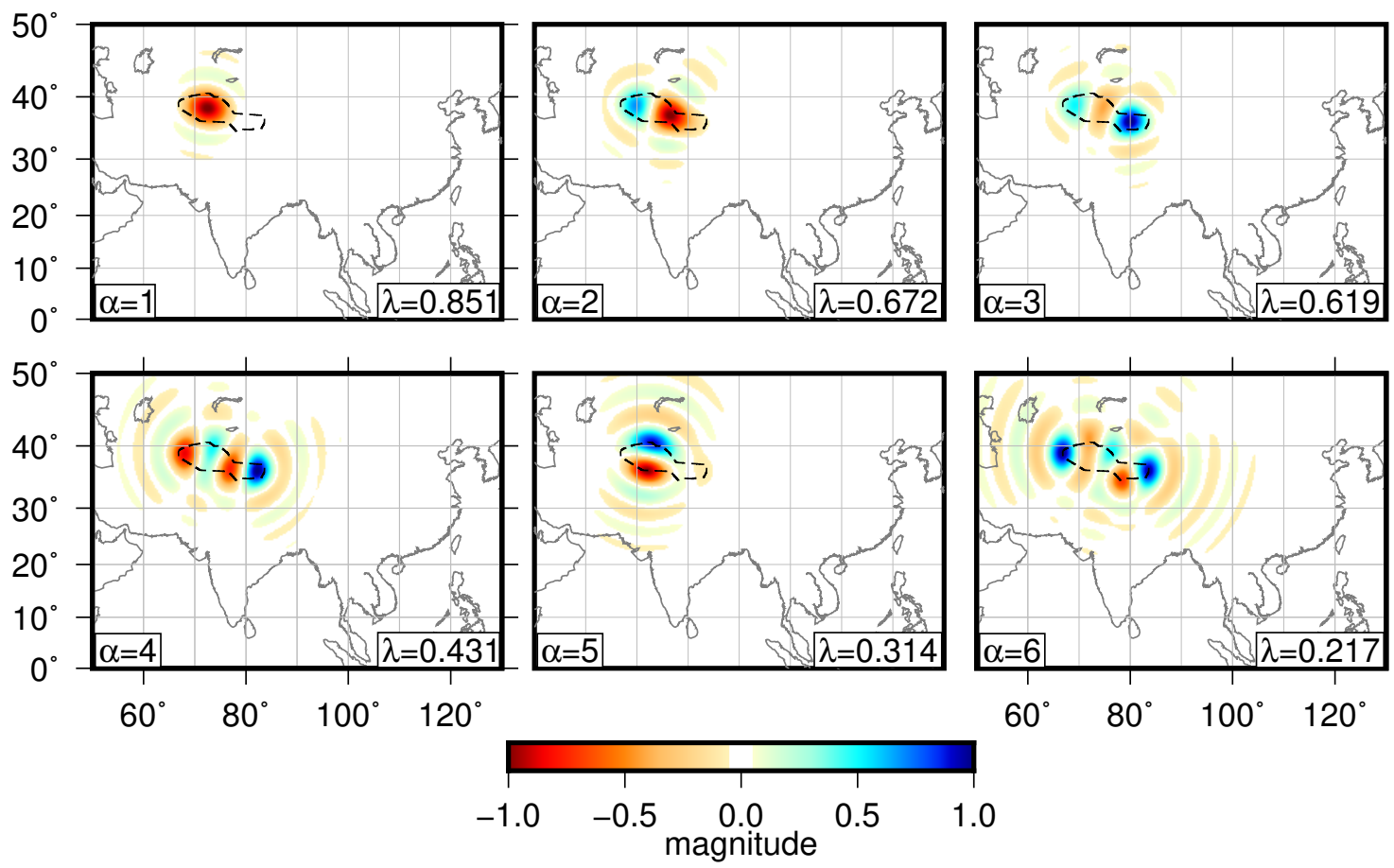

Figure 3: Well-concentrated $L=60$ Slepian functions, localized for the Pamir region in central Asia. Annotations and labeling are as in Fig. 2.

coefficients $f_{l m}$. Generally, and as we take this to be the case here, the appropriate number is close to the areabandwidth product or Shannon number $K$. The size of the region $R$ is determined via synthetic input-output inversion experiments $[25,27]$. Based on these experiments corrections for leakage error are unnecessary and are not made.

Each of the Slepian functions is an "eigenmap" pattern whose integral is a measure of the average importance of the function in question over the area of interest. Multiplication of the integral value with the the expansion coefficients yields the total value of mass flux over the region.

Figures 2, 3, 4, 5 show the Slepian functions for the four different regions used in this study. The Shannon number of useful functions for each region is constituted by those elements of the Slepian basis that have eigenvalues $\lambda \gtrsim 0.5$, which are listed in the figure panels. The Shannon numbers for each region were Himalaya $K=7$, Pamir $K=3$, Qilian $K=7$, and Tien Shan $K=4$. We note that the smaller the region under study, the fewer Slepian functions are available or necessary for the expansion, which altogether limits the spatial coverage over the region. The values for the regions on the Tibetan Plateau end up being much smaller those used previous studies of ice mass loss using Slepian functions, which considered the much larger areas of Greenland and Antarctica [25, 27].
After turning the original spherical harmonic coefficients, which have no spatial selectivity, into the expansion coefficients of the Slepian basis designed for the region of interest, we obtain new time series that are then analyzed for their temporal behavior.

The final step in the analysis is the attribution of the mass fluxes over the regions to ice mass behavior. We corrected the data using a global glacial isostatic adjustment (GIA) model [34, 35] which subtracts the effects of ongoing mass trends related to previous deglaciations. We also use a model of terrestrial water storage (TWS) calculated from the Global Land Data Assimilation System 1.0 (Noah) to correct for non-ice related hydrological fluxes which may contaminate the mass signal; ice turning to melt is not necessarily all removed from the system, and non-ice related hydrological fluxes may contaminate the mass signal. We limit or mask the TWS model to areas which are not currently glaciated because these models are known to be inaccurate in areas containing land ice.

\section{Results}

Figures 6, 8, 9, and 10 show the total change in ice mass from April 2002 to May 2016 in all four regions outlined in Fig. 1, determined by the combination of the determined 

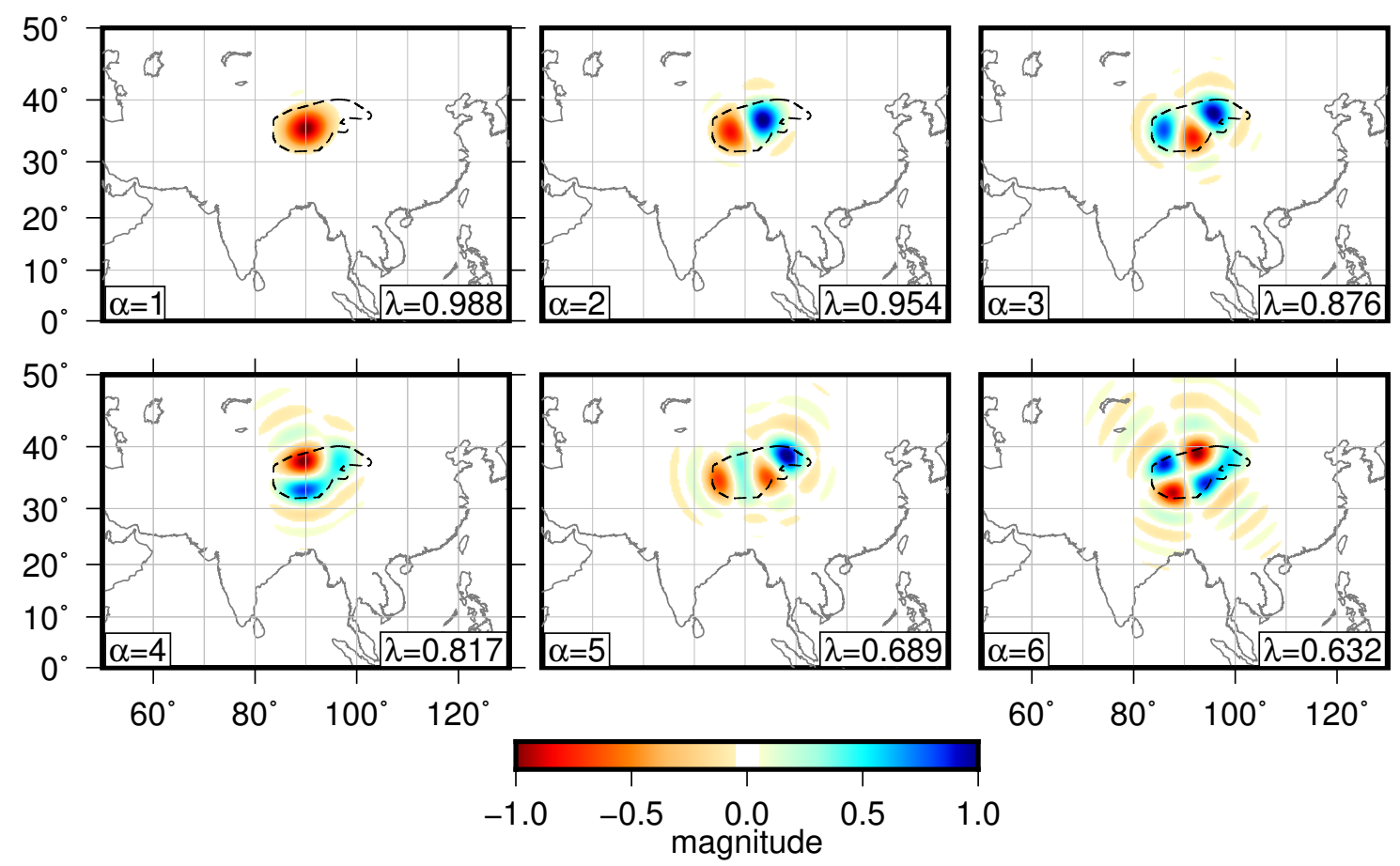

Figure 4: Well-concentrated $L=60$ Slepian functions, localized for the Qilian region in central Asia. Annotations and labeling are as in Fig. 2.

Slepian functions (Figs. 2, 3, 4, and 5) integrated over the area and multiplied by their corresponding expanding coefficients. Ice mass is translated to sea-level equivalents using the conversion of $1 \mathrm{~mm}$ SLR per $361 \mathrm{Gt}$ of purported ice mass.

Temporal fitting was carried out in a polynomial basis up to the third degree, as warranted by $F$-tests on the proportional improvement of the fits in terms of their reduction of variance. Yearly (365 day) and biannual (182.5 day) cycles were also included in this fit, as seasonal cycling has a large impact on glacial mass. All plots exhibited well-resolved linear trends. The total fit of the Tien Shan region in Fig. 10 exhibits a deviation from the linear trend in the data, the modeling of which was not improved by reconstructing with higher degree polynomials. The total fit of the data was used to determine the rate of change of the glaciers and the total change during the time period of the glaciers. None of the four regions examined revealed detectable acceleration (quadratic trends)in mass change during our study period. However, glaciers in those region may be accelerating over time scales greater than the measurement epoch.

Figure 7 shows the individual functions in the region scaled by the integrated weight of the Slepian functions. Note that those Slepian functions were shown in Fig. 2.

Figures 7, 12 and 13 show the individual Slepian components for Figs. 6, 9, and 10.
Figure 14 shows the spatial change of all four of the subregions. Himalaya and Tien Shan experienced the largest losses of ice mass over the twelve-year period and had mass loss concentrated in the eastern portion of the regions. Pamir exhibited little net change over the time period but had consistent seasonal cycles present throughout, as visible in Fig. 8.

Results in Figs. 6, 8, 9, 10 are vary slightly from the results in Fig. 14 because of the ordering of combining individual functions and averaging them. In this study we followed the procedures of [36] creating the temporal fit by first expanding the coefficients, integrating over the region and then inverting them, and creating the spatial trend by inverting each Slepian function before re-expanding and summing them.

The yearly melt rates, $\dot{M}$, for each region determined by the temporal method of fitting with $95 \%$ confidence intervals were: Himalaya $\dot{M}=-11 \pm 3 \mathrm{Gt} / \mathrm{yr}$, Pamir $\dot{M}=-1 \pm$ $2 \mathrm{Gt} / \mathrm{yr}$, Qilian $\dot{M}=+8 \pm 2 \mathrm{Gt} / \mathrm{yr}$, Tien Shan $\dot{M}=-6 \pm 1 \mathrm{Gt} / \mathrm{yr}$.

\section{Discussion}

In this study we used a statistical technique known as spatiospectral localization using spherical Slepian functions to estimate the time-evolving mass system in the Tibetan 

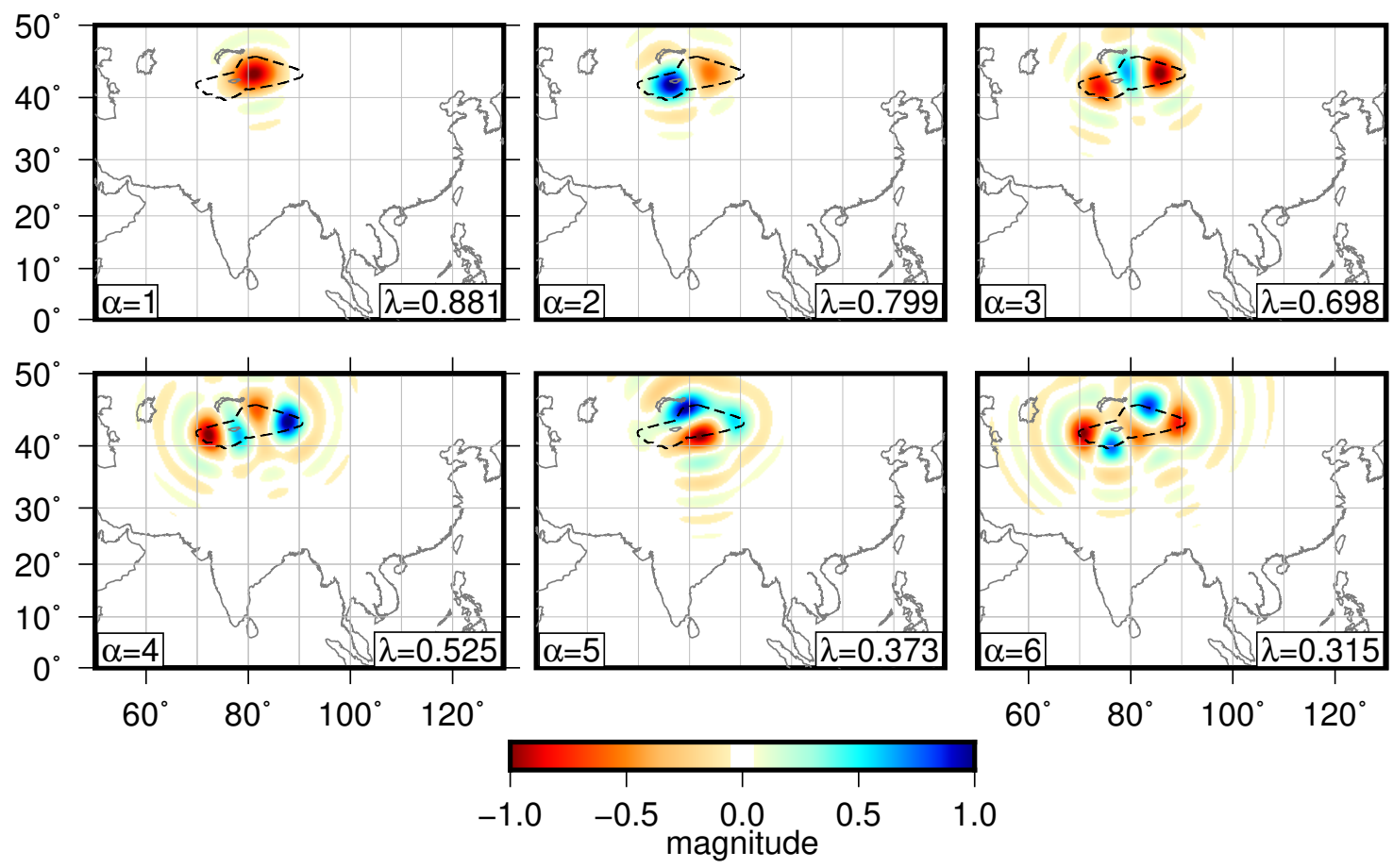

Figure 5: Well-concentrated $L=60$ Slepian functions, localized for the Tien Shan region in central Asia. Annotations and labeling are as in Fig. 2.

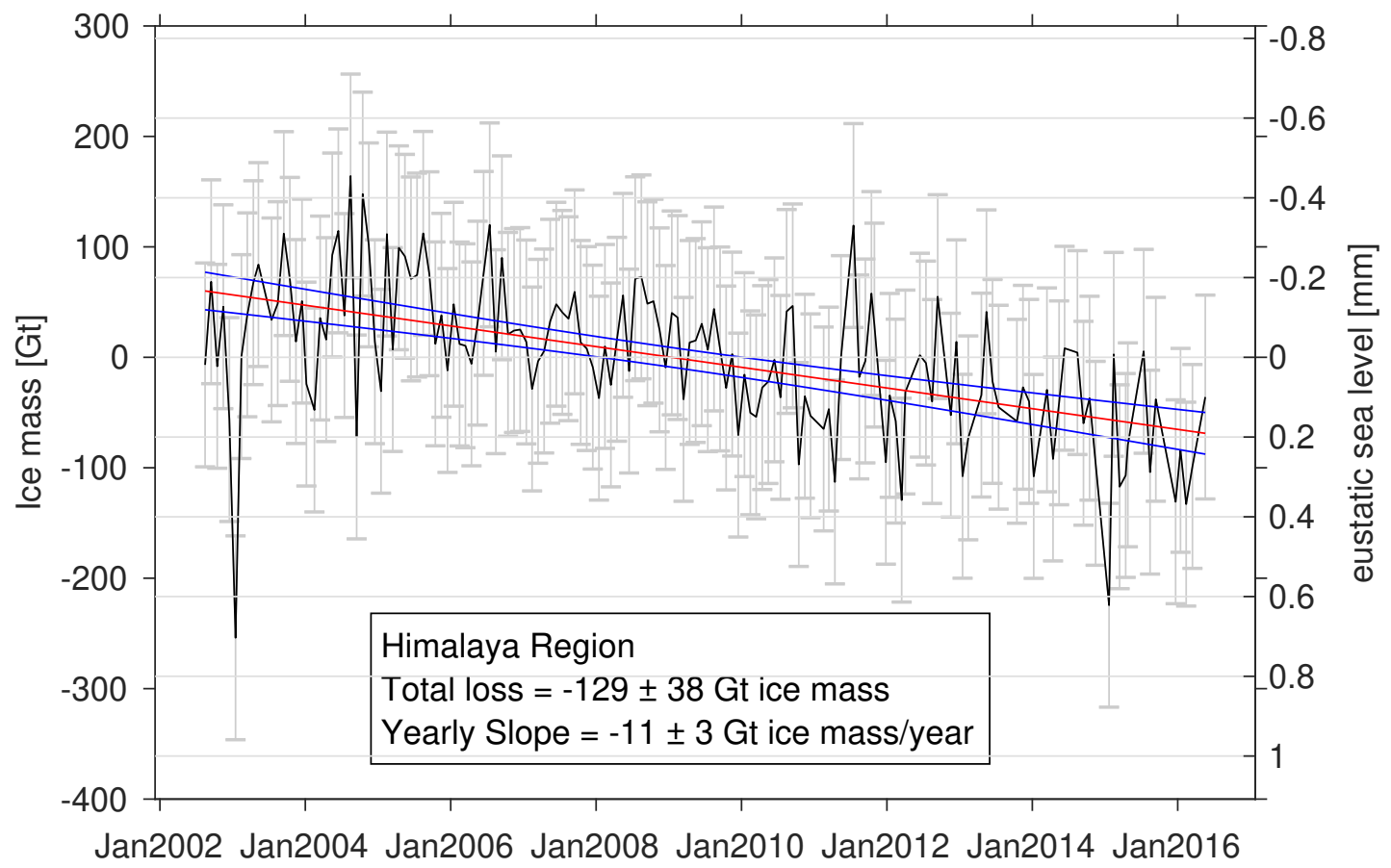

Figure 6: Total change in ice mass from April 2002 to May 2016 in the Himalayan region as determined from our analysis. The black line with $95 \%$ confidence bars in grey shows the monthly total ice mass as obtained from the projection of the raw data collected by GRACE onto seven Slepian functions designed for the area and with a bandwidth of $L=60$. The red line shows the linear component of the best fit that also included yearly and bi-annual cycles, which were removed for display. The blue lines are the $95 \%$ confidence interval for this linear fit. The Himalayan region exhibited a consistent loss over the twelve-year period totaling $-129 \mathrm{Gt}$ of ice mass in that time period, equivalent to $+0.36 \mathrm{~mm}$ of global sea-level rise. 


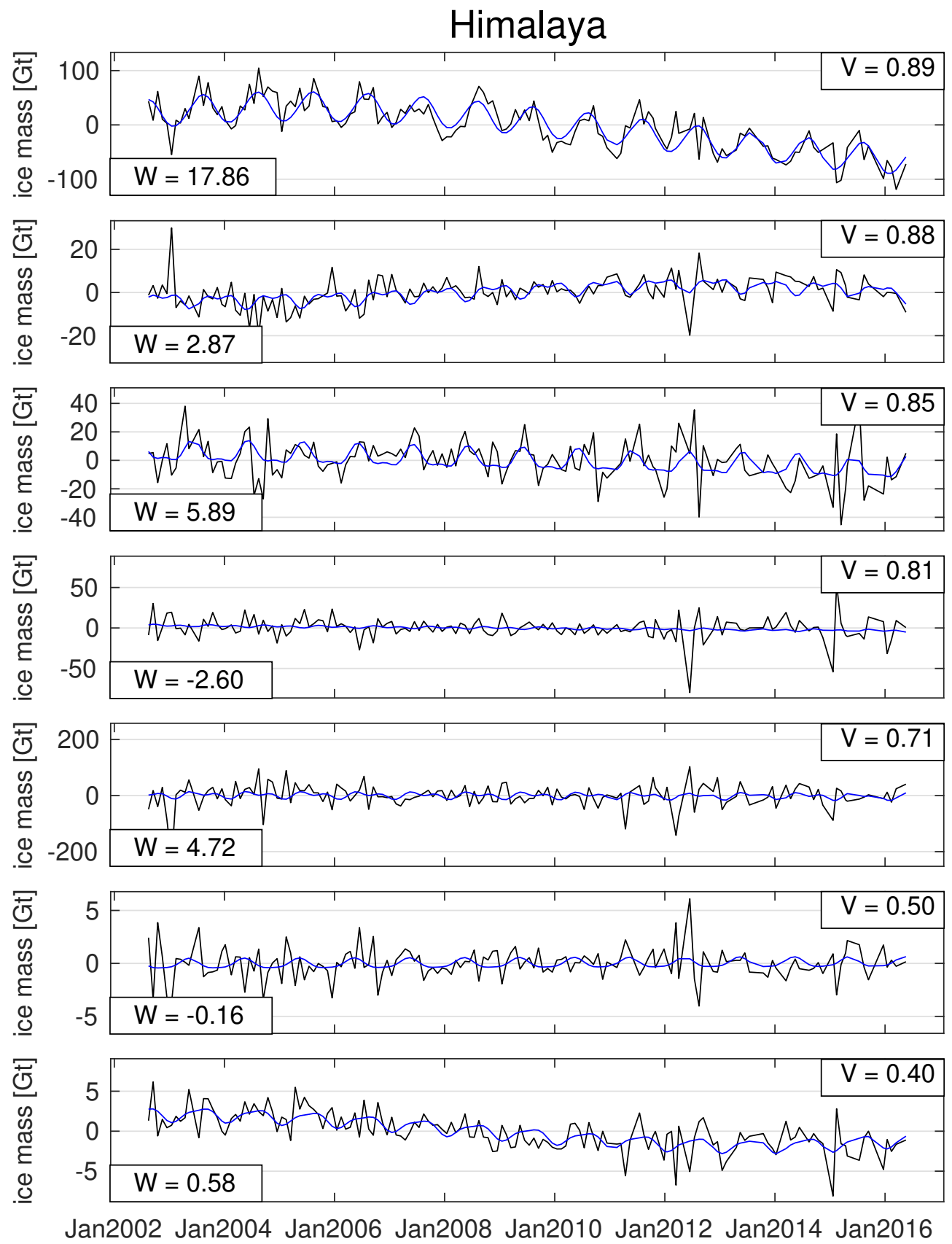

Figure 7: Monthly time series of the seven Slepian coefficients used to extract the total ice mass loss in the Himalayan region, which was shown in Figure 2. The black lines show the raw data from GRACE after projection onto the individual Slepian functions. The blue lines show their least-squares fits in terms of periodic functions with a 182.5 day and a 365 day cycles, and polynomials up to the third degree. The eigenvalues of the Slepian functions are denoted by $V$ and $W$ is their integral, which is the weight by which these are combined into the total shown in Figure 2.

Plateau, focusing on four subregions, which we took to be Qilian, Tien Shan, Pamir, and Himalaya. The data source is from the GRACE gravity mission, which has an intrinsic resolution limitation corresponding to a maximal spherical harmonic degree of $L=60$. The Slepian technique reduces the number of components that need to be estimated from the data to a small handful, scaling the full dimen- sion of the inverse problem, $(L+1)^{2}$, by the fractional area of the region under study. The benefits of dimensional reduction are offset by an increase in estimation variance. Overall, the biggest limitation to this study was the small area of interest, which as we know from the definition of the Shannon number (see Eq. (2)), greatly limits the number of Slepian functions applicable to the area. Despite this 


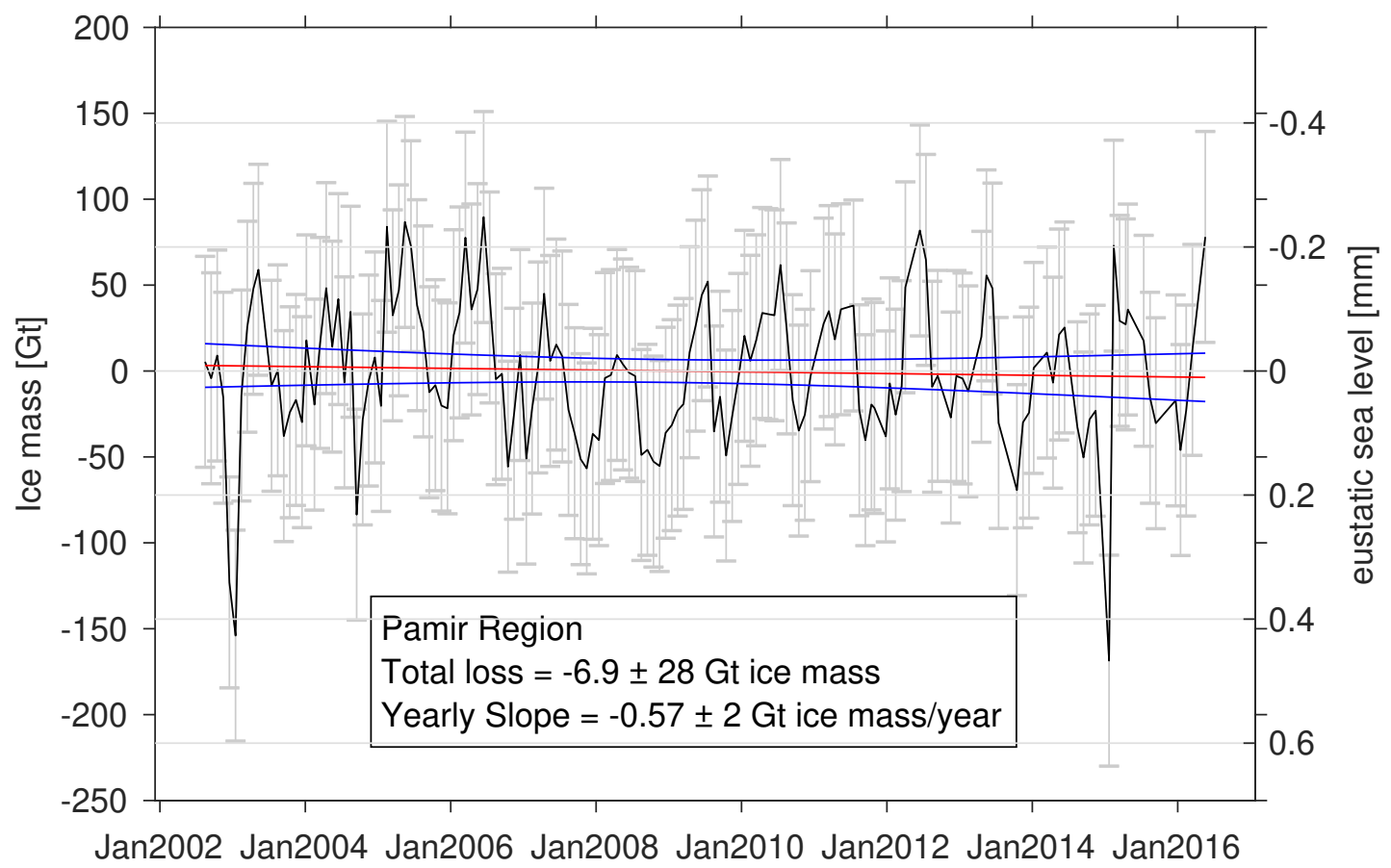

Figure 8: Total change in ice mass from April 2002 to May 2016 in the Pamir region as determined from our analysis. Symbols and annotations are identical to those used in Figure 6. The Pamir region exhibited minimal ice mass change over the twelve-year period with a net loss of $-7 \mathrm{Gt}$ of ice mass in that time period, equivalent to less than $+0.02 \mathrm{~mm}$ of global sea-level rise.

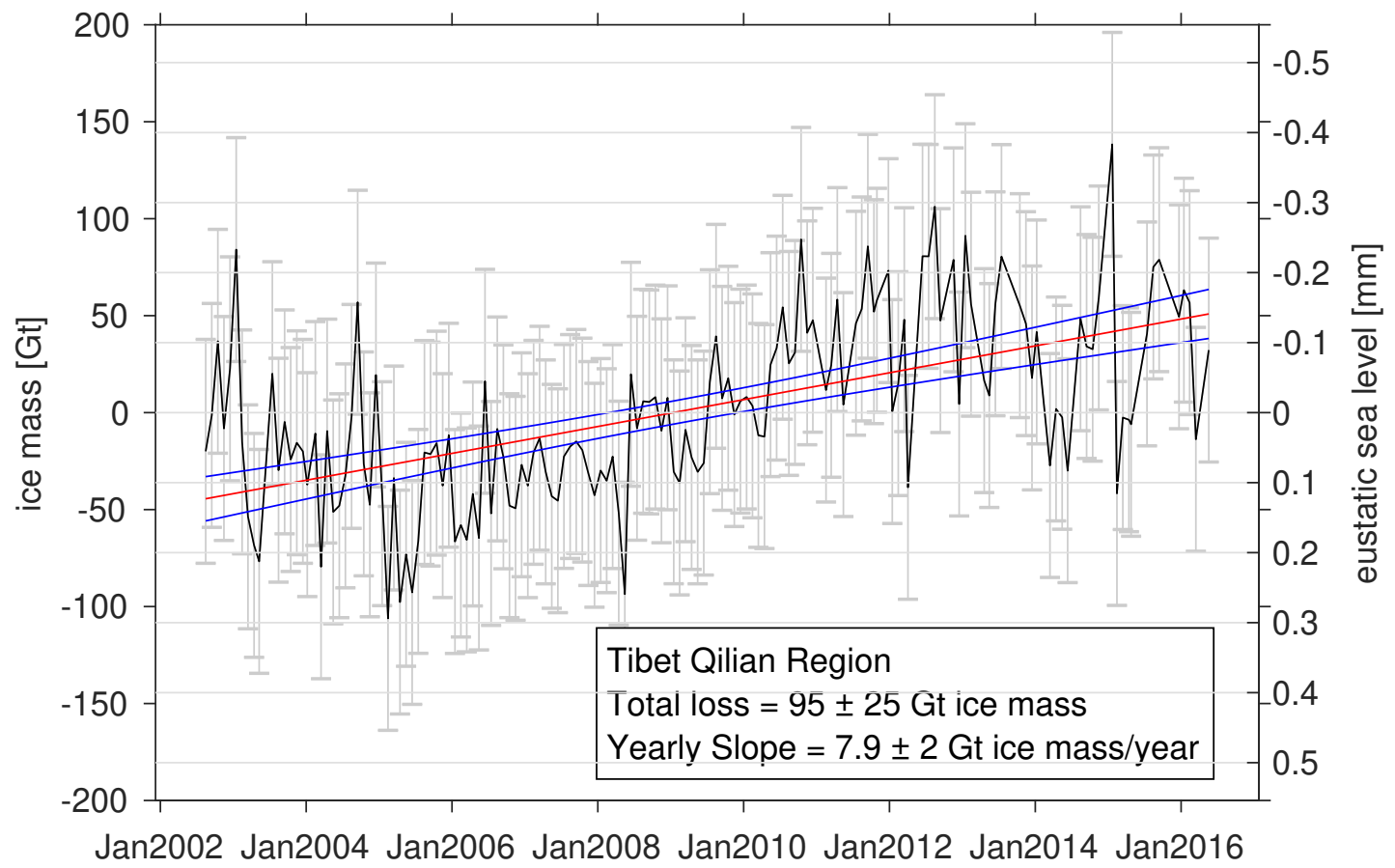

Figure 9: Total change in ice mass from April 2002 to May 2016 in the Qilian region as determined from our analysis. Symbols and annotations are identical to those used in Figure 6 . The Qilian region exhibited a steady gain over the twelve-year period totaling $+95 \mathrm{Gt}$ of ice mass in that time period, equivalent to $-0.26 \mathrm{~mm}$ of global sea-level fall.

small area, there was high spatial variability within the Tibetan Plateau, with two areas decreasing by 110 and $70 \mathrm{Gt}$ of ice mass, one staying mostly the same and one increas- ing by almost $100 \mathrm{Gt}$. The net regional change was $-118 \mathrm{Gt}$ ice mass. 


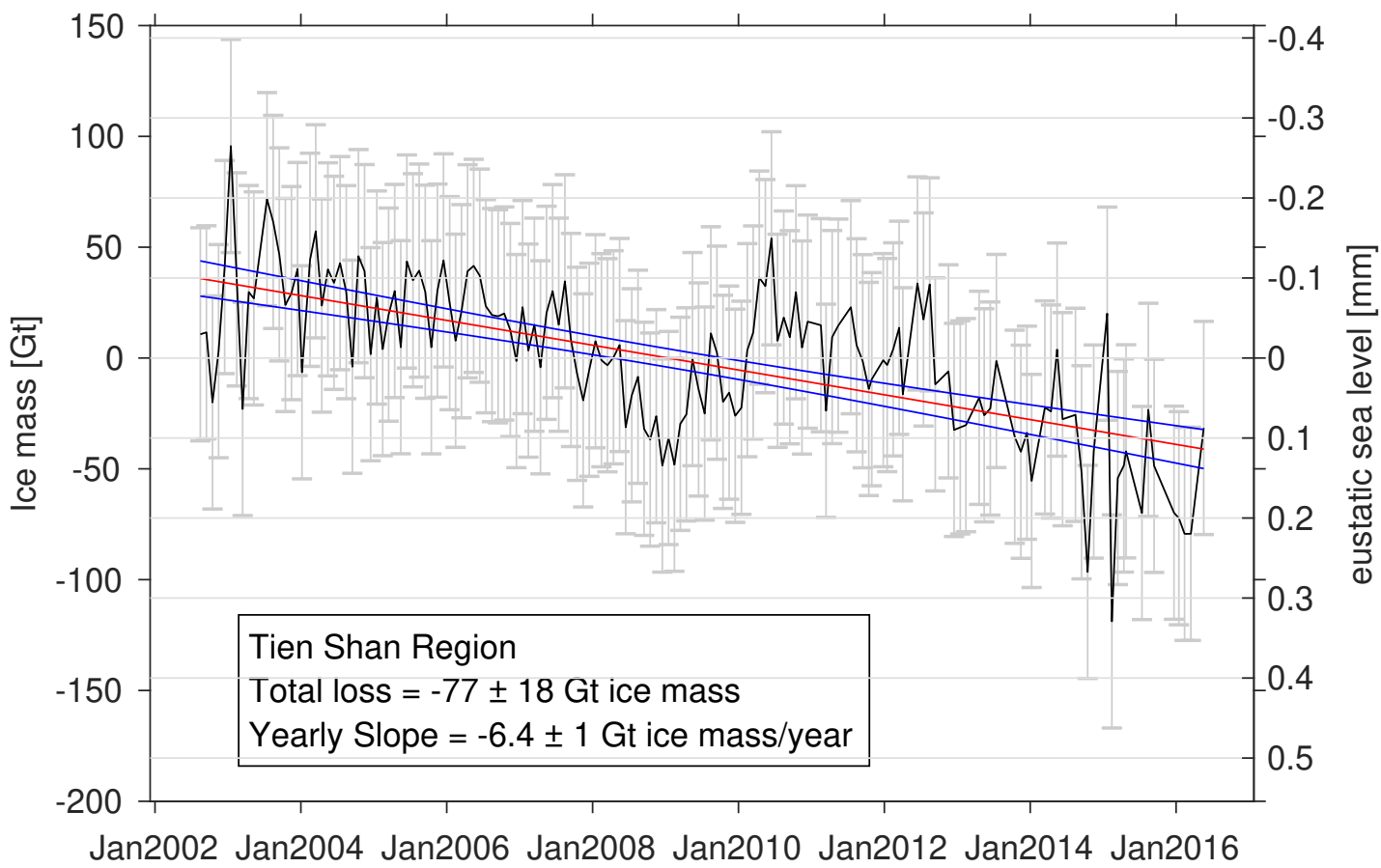

Figure 10: Total change in ice mass from April 2002 to May 2016 in the Tien Shan region as determined from our analysis. Symbols and annotations are identical to those used in Figure 7. The Tien Shan region exhibited a variable loss over the twelve-year period totaling $-77 \mathrm{Gt}$ of ice mass in that time period, equivalent to $+0.21 \mathrm{~mm}$ of global sea-level rise.

Pamir
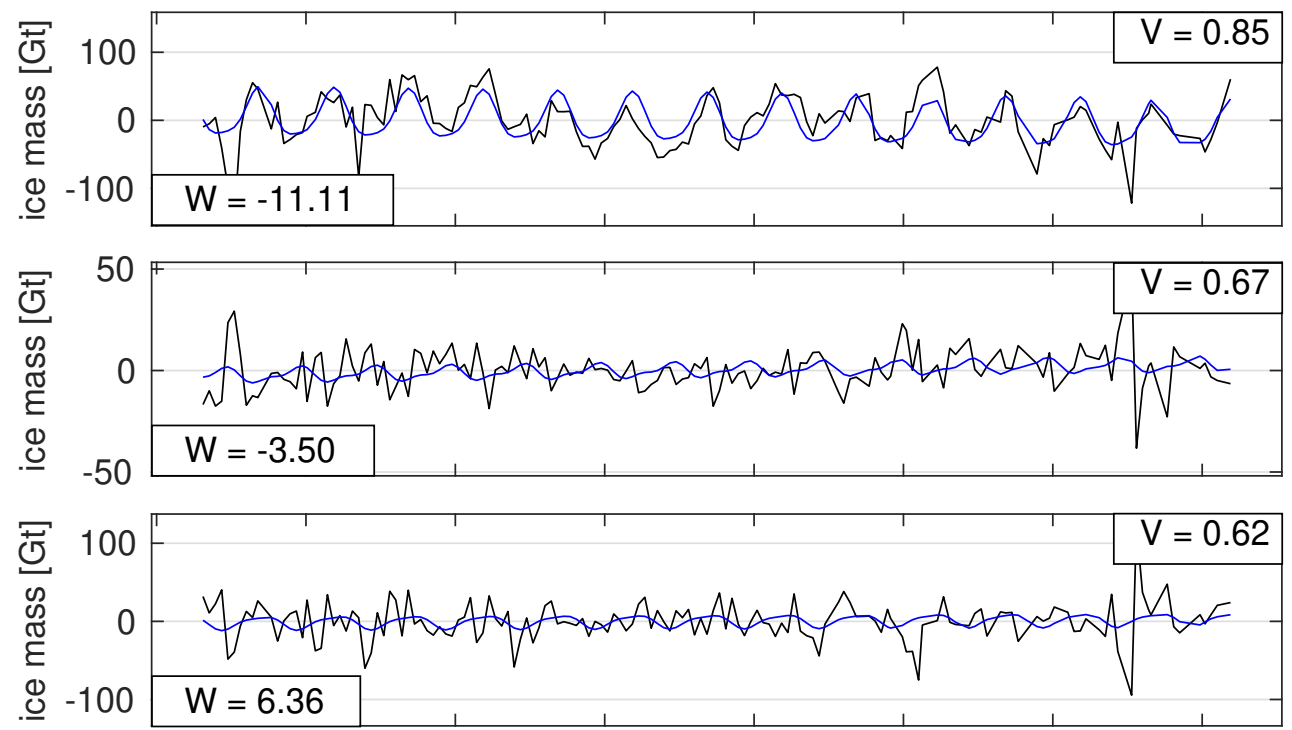

Jan2002 Jan2004 Jan2006 Jan2008 Jan2010 Jan2012 Jan2014 Jan2016

Figure 11: Monthly time series of the three Slepian coefficients used to extract the total ice mass loss in the Pamir region, which was shown in Figure 8. The black lines show the raw data from GRACE after projection onto the individual Slepian functions. The blue lines show their least-squares fits in terms of periodic functions with a 182.5 day and a 365 day cycles, and polynomials up to the third degree. The red lines show only the non-cyclical components of these fits.

Some of the regional variability may be explained by three factors, elevation, aspect and latitude. These three factors accounted for $75 \%$ of the variance in temporal glacial melt distribution for the Tien Shan region as found in [37]. Our findings were closely aligned with those of [37] for the Tien Shan region. Our findings of $\dot{M}=-5.7 \mathrm{Gt} / \mathrm{yr}$, 


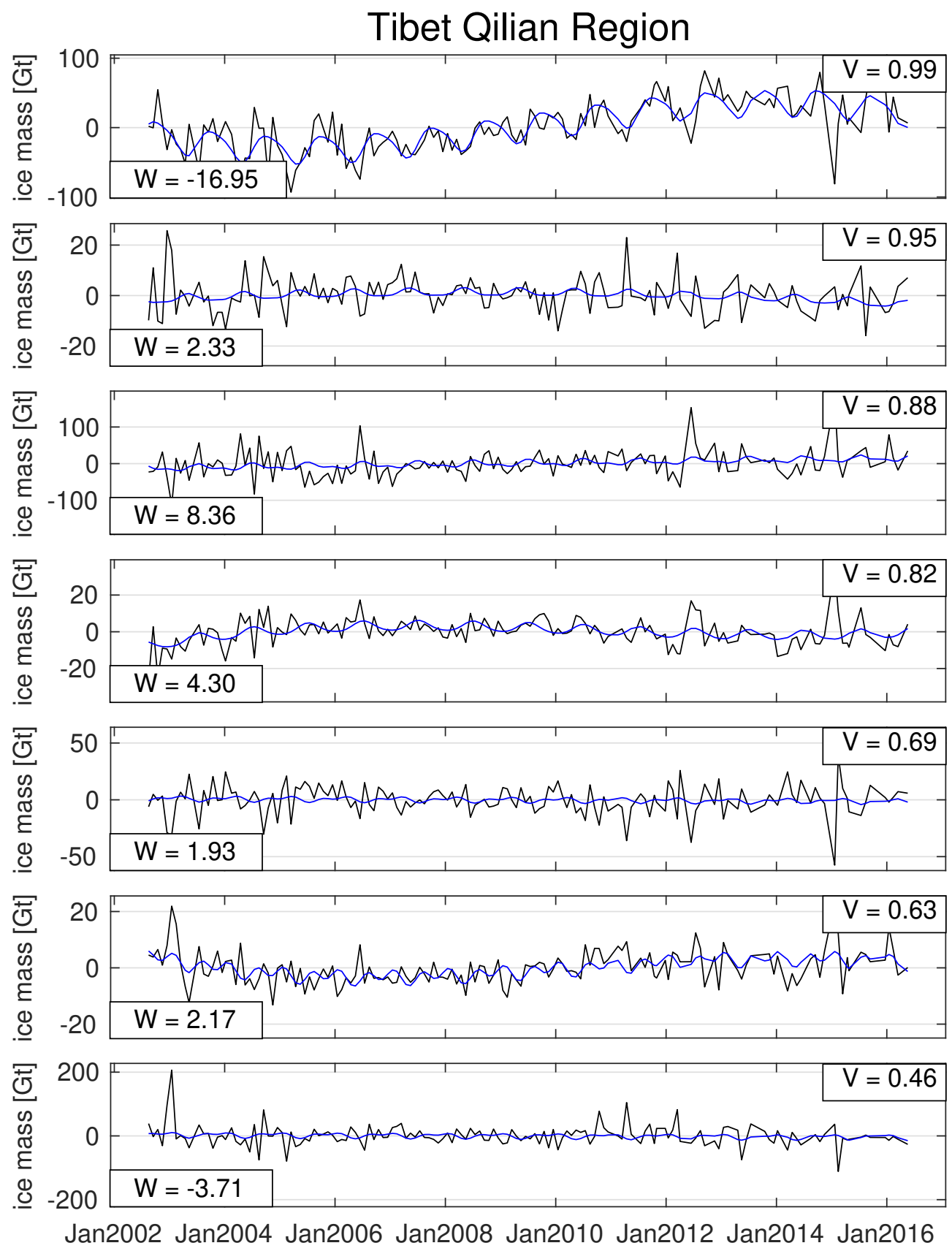

Figure 12: Monthly time series of the seven Slepian coefficients used to extract the total ice mass loss in the Qilian region, which was shown in Figure 9. The black lines show the raw data from GRACE after projection onto the individual Slepian functions. Labels and annotations as in Figure 11.

were in line with their findings of $\dot{M}=-5.4 \pm 2.8 \mathrm{Gt} / \mathrm{yr}$ for glaciers in Tien Shan modeled between 1961 and 2012. [37] do not suggest that there is an acceleration in the rate of glacier loss for this region but that there has been a consistent decline. Satellite images of the Tien Shan indicate glaciers lost approximately $8 \%$ of their area in the 30 years prior to the launch of GRACE (1971-2002) [38]. [39] found that all sectors of the Tien Shan have been losing ice since
Table 1: Comparison of results from this study with [37].

\begin{tabular}{lcc}
\hline Region & [37] [Gt/yr] & This Study [Gt/yr] \\
\hline \hline Qilian & $-5.4 \pm 2.8$ & $+8 \pm 2$ \\
\hline
\end{tabular}

2002. In addition the interannual variations and the secular trend in the Tien Shan since 2002 are consistent with rising temperatures in the region [39]. 


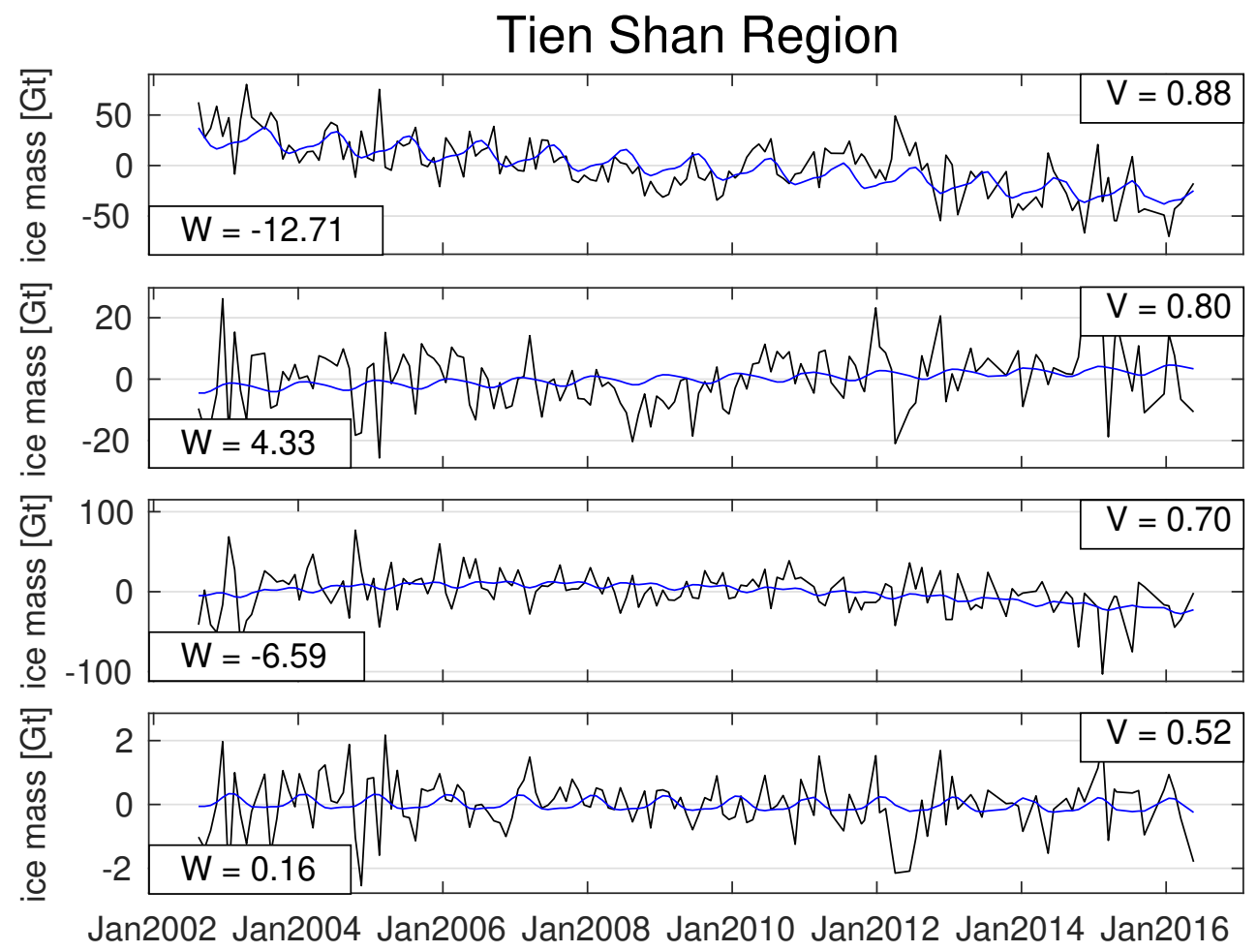

Figure 13: Monthly time series of the four Slepian coefficients used to extract the total ice mass loss in the Tien Shan region, which was shown in Figure 10. The black lines show the raw data from GRACE after projection onto the individual Slepian functions. Labels and annotations as in Figure 11.

Table 2: Comparison of results from this study with [13].

\begin{tabular}{ccc}
\hline Region & [13] [Gt/yr] & This study [Gt/yr] \\
\hline \hline Himalaya & $-5 \pm 6$ & $-11 \pm 3$ \\
Pamir & $-1 \pm 5$ & $-1 \pm 2$ \\
Qilian & $+7 \pm 7$ & $+8 \pm 2$ \\
Tien Shan & $-5 \pm 6$ & $-6 \pm 1$ \\
\hline
\end{tabular}

[13] measured global ice mass changes between January 2003 and December 2010 using GRACE data localized with mascons, small regions of the earth. Our four regions of interest were defined by [13], and our results well within the $95 \%$ confidence intervals for each region. However the confidence intervals found in this study were much tighter than those in [13] due the improvements of using Slepian functions rather than arbitrarily defined shapes, mascons, on the sphere.

[40] found that climate variability resulted in $3200 \pm$ $900 \mathrm{Gt}$ of water being stored on land between 2002 and 2014, indicating that there may be some some offset to the amount to which glaciers contribute to SLR. However in the distribution of this water offset based on global GRACE mascon analysis TWS decreased in the regions of interest for this study.
Table 3: Comparison of results from this study with [41].

\begin{tabular}{ccc}
\hline Region & [41] [Gt/yr] & This study [Gt/yr] \\
\hline \hline Himalaya & $-12.8 \pm 3.5$ & $-11 \pm 3$ \\
\hline
\end{tabular}

[41] used ICESat altimetry and Shuttle Radar Topography Mission (SRTM) Digital Elevation Model (DEM) to determine the decrease in glacier ice mass in the Himalayan region. They found the yearly decrease to be $\dot{M}=-12.8 \pm$ $3.5 \mathrm{Gt} / \mathrm{yr}$. However the altimetric model of determining glacier ice mass change assumes constant ice density and assumes that loss of ice volume will be proportional to the loss of mass.

[15] contends that not all regions surrounding the Tibetan Plateau will be affected evenly if glaciers in this area continue shrink. They found that less than $10 \%$ of water in the Ganges, Yellow, and Yangtze river came from glacial runoff, and that glacial runoff is often confused for snow melt. However in drier regions such as Pakistan and Afghanistan, glacial runoff is an extremely important source of water, and losing the glaciers as a water source could greatly compromise water security in the area. Ground-truthing of any information in this region remains extremely difficult as relations between neighbor- 

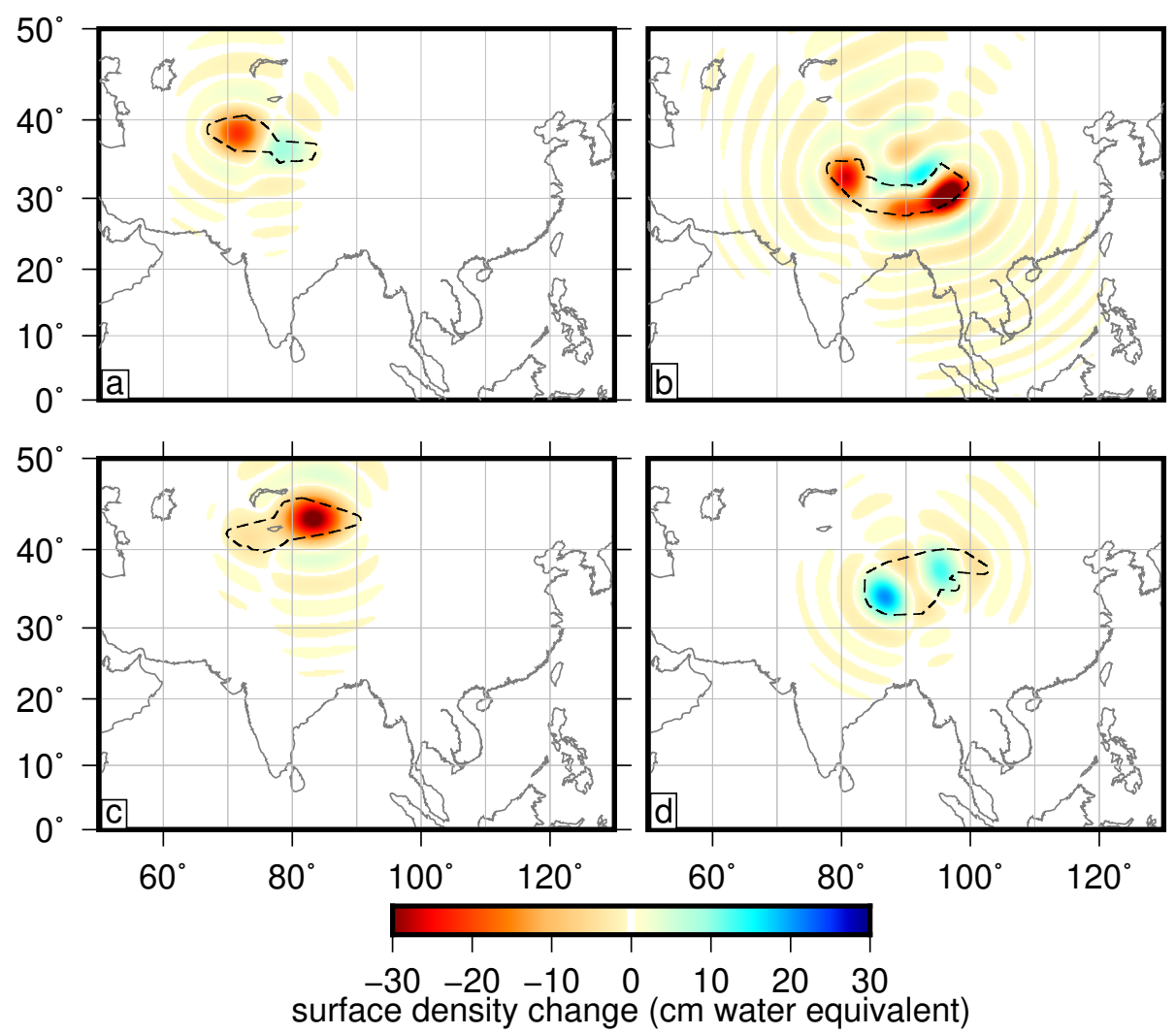

Figure 14: Four maps of the spatial change in ice mass between April 2002 and May 2016 in the four designated regions of the Tibetan Plateau. Box A shows the Pamir region which remained relatively unchanged during this time period. However, this region was the smallest and had the least Slepian Functions. Box B shows the Tien Shan region which had the second greatest amount of ice loss and has a more spatially distinct distribution of ice mass loss, concentrated in the eastern portion of the region. Box $C$ shows the spatial ice mass change in the Himalayan region. This region experienced the greatest amount of ice mass loss at a change of $-129 \mathrm{Gt}$ ice mass. The spatial distribution of mass projected by the seven Slepian functions shows the greatest decrease in the eastern half of the region. Box $D$ shows the Qilian region which had a net positive change of of $+95 \mathrm{Gt}$ of ice mass. The increase in ice mass appears to be more evenly distributed within the region than in the Himalayan and the Tien Shan regions.

ing countries in the region to not foster scientific collaboration. In situ data collection remains extremely challenging in the area [42].

If glaciers on the Tibetan Plateau continue to decline and grow at their current rates without any acceleration, they will contribute about $2.3 \mathrm{~mm}$ of SLR by 2100 . Although this number seems relatively small contribution to predicted global sea-level rise, local implications for changes in glacial melt contributions to local drainage basins may have a more severe effect. [43] estimated the total volume of glaciers in this region to be $4561 \mathrm{~km}^{3}$. The density of glacial ice is on average approximately $850 \mathrm{~kg} / \mathrm{m}^{3}$ [44], which is equal to $0.85 \mathrm{Gt} / \mathrm{km}^{3}$. If glaciers in the region continued to decline at a constant rate $-10 \mathrm{Gt} /$ year (combined all regions gaining and loosing) it would take 387 years for the glaciers on the Tibetan Plateau to melt.

\section{Conclusions}

This study uses a novel technique of Slepian analysis to measure changes in ice mass on the Tibetan Plateau using GRACE data from 2002 to 2016. This technique is unique from the previous studies of the region and its findings have a higher spatial resolution than other methods of analyzing GRACE data. The Tibetan Plateau is warming and may exhibit more dramatic effects due climate change than other regions in the world. Previous studies have been inconclusive. We find that the Third Pole, the third largest region of ice mass in the world, is losing ice mass at a steady rate and did not exhibit any acceleration during a twelve-year time period. However some regions did exhibit slight deviations from the linear trend, such as Tien Shan, which indicate that other nonlinear trends may be observable over longer periods of time. By localizing GRACE coefficients using a Slepian basis we were able to determine 
spatiotemporal variability on the Tibetan Plateau. Overall the region had a net loss of $-118 \mathrm{Gt}$ of ice mass, equivalent to $0.33 \mathrm{~mm}$ of sea-level rise. Despite this small contribution to sea-level rise, changes in the high mountain Asian glaciers threaten water security for nearly one quarter of the world's population. Change in ice mass varied by region with one region gaining ice mass, two regions losing ice mass, and one region remaining the same. Further study is necessary to determine how changes in different regions will affect populations, and what factors correlate to ice mass loss versus gain in a relatively small, heterogeneous region. Cooperation between local scientists for local data collection as well as international cooperation collecting remotely sensed measurements, such as GRACE, should be continued in order to better estimate further changes on the Tibetan Plateau.

Acknowledgement: This work was supported by the U. S. National Science Foundation, via grants EAR1245788 to F. J. S. and C. H and NASA grant NNX17AE18G to C. H. Our computer codes are available online [45].

\section{References}

[1] Qiu, J., 2012. Glaciologists to target third pole. Nature, 484, 7392, 19.

[2] Liu, X. and Chen, B., 2000. Climatic warming in the Tibetan Plateau during recent decades. Int. J. Climatol., 20, 14, 17291742, doi: 10.1002/1097-0088(20001130)20:14<1729::AIDJOC556>3.0.CO;2-Y.

[3] Kang, S., Xu, Y., You, Q., Flügel, W.-A., Pepin, N. and Yao, T., 2010. Review of climate and cryospheric changes in the Tibetan Plateau. Environm. Res. Lett., 5, 1, 015101, doi: 10.1088/17489326/5/1/015101.

[4] Field, C. B., Barros, V., Dokken, D. J., March, K. J., Mastrandrea, M. D., Bilir, T. E., Chatterjee, M., Ebi, K. L., Estrada, Y. O., Genova, R. C., Girma, B., Kissel, E. S., Levy, A. N., MacCracken, S., Mastrandrea, P. R. and White, L. L., 2014. Climate Change 2014: Impacts, adaptation, and vulnerability: Part A: Global and sectoral aspects. Working Group II Contribution to the Fifth Assessment Report. Technical report, Intergovernmental Panel on Climate Change, Cambridge, UK.

[5] Du, M., Kawashima, S., Yonemura, S., Zhang, X. and Chen, S., 2004. Mutual influence between human activities and climate change in the Tibetan Plateau during recent years. Global and Planetary Change, 41, 3-4, 241-249, doi: 10.1016/j.gloplacha.2004.01.010.

[6] Bradley, R. S., Vuille, M., Diaz, H. F. and Vergara, W., 2006. Threats to water supplies in the tropical Andes. Science, 312, 5781, 1755-1756, doi: 10.1126/science. 1128087.

[7] Bamber, J., 2012. Shrinking glaciers under scrutiny. Nature, 482, 7386, 482-483, doi: 10.1038/nature10948.

[8] Singh, P. and Singh, V. P., 2001. Snow and Glacier Hydrology. Water Science and Technology Library. Kluwer, Dordrecht, Neth.
[9] Gardner, A. S., Moholdt, G., Cogley, J. G., Wouters, B., Arendt, A. A., Wahr, J., Berthier, E., Hock, R., Pfeffer, W. T., Kaser, G., Ligtenberg, S. R. M., Bolch, T., Sharp, M. J., Hagen, J. O., van den Broeke, M. R. and Paul, F., 2013. A reconciled estimate of glacier contributions to sea level rise: 2003 to 2009. Science, 340, 6134, 852-857, doi: 10.1126/science.1234532.

[10] Meier, M. F., Dyurgerov, M. B., Rick, U. K., O’Neel, S., Pfeffer, W. T., Anderson, R. S., Anderson, S. P. and Glazovsky, A. F., 2007. Glaciers dominate eustatic sea-level rise in the 21st century. Science, 317, 5841, 1064-1067, doi: 10.1126/science.1143906.

[11] Piao, S., Ciais, P., Huang, Y., Shen, Z., Peng, S., Li, J., Zhou, L., Liu, H., Ma, Y., Ding, Y., Friedlingstein, P., Liu, C., Tan, K., Yu, Y., Zhang, T. and Fang, J., 2010. The impacts of climate change on water resources and agriculture in China. Nature, 467, 7311, 4351, doi: $10.1038 /$ nature09364.

[12] Morton, K., 2011. Climate change and security at the Third Pole. Survival: Global Politics \& Strategy, 53, 1, 121-132, doi: 10.1080/00396338.2011.555606.

[13] Jacob, T., Wahr, J., Pfeffer, W. T. and Swenson, S., 2012. Recent contributions of glaciers and ice caps to sea level rise. Nature, 482, 7386, 514-518, doi: 10.1038/nature10847.

[14] Pfeffer, W. T., Arendt, A. A., Bliss, A., Bolch, T., Cogley, J. G., Gardner, A. S., Hagen, J. O., Hock, R., Kaser, G., Kienholz, C., Miles, E. S., Moholdt, G., Mölg, N., Paul, F., Radić, V., Rastner, P., Raup, B. H., Rich, J., Sharp, M. J. and the Randolph Consortium, 2014. The Randolph Glacier Inventory: a globally complete inventory of glaciers. J. Glaciol., 60, 221, 537-552, doi: 10.3189/2014JoG13/176.

[15] Immerzeel, W. W., van Beek, L. P. H. and Bierkens, M. F. P., 2010. Climate change will affect the Asian water towers. Science, 328, 5984, 1382-1385, doi: 10.1126/science.1183188.

[16] Barnett, T. P., Adam, J. C. and Lettenmaier, D. P., 2005. Potential impacts of a warming climate on water availability in snow-dominated regions. Nature, 438, 7066, 303-309, doi: 10.1038 /nature04141.

[17] Sorg, A., Bolch, T., Stoffel, M., Solomina, O. and Beniston, M., 2012. Climate change impacts on glaciers and runoff in Tien Shan (Central Asia). Nature Climate Change, 2, 10, 725-731, doi: 10.1038/nclimate1592.

[18] Singh, S. P. and Thadani, R., 2015. Complexities and controversies in Himalayan research: A call for collaboration and rigor for better data. Mountain Research and Development, 35, 4, 401409, doi: 10.1659/MRD-JOURNAL-D-15-00045.

[19] Khan, S. A., Wahr, J., Bevis, M., Velicogna, I. and Kendrick, E., 2010. Spread of ice mass loss into northwest Greenland observed by GRACE and GPS. Geophys. Res. Lett., 37, 6, L06501, doi: 10.1029/2010GL042460.

[20] Hambrey, M. J., 1987. Radioglaciology. Earth Sci. Rev., 24, 4, 283-284, doi: 10.1016/0012-8252(87)90067-5.

[21] Cogley, J. G., Hock, R., Rasmussen, L. A., Arendt, A. A., Bauder, A., Braithwaite, R. J., Jansson, P., Kaser, G., Möller, M., Nicholson, L. and Zemp, M., 2011. Glossary of glacier mass balance and related terms. IHP-VII Technical Documents in Hydrology No. 86 IACS Contribution No. 2, UNESCO-IHP.

[22] Moholdt, G., Nuth, C., Hagen, J. O. and Kohler, J., 2010. Recent elevation changes of Svalbard glaciers derived from ICESat laser altimetry. Remote Sensing of Environment, 114, 11, 2756-2767, doi: 10.1016/j.rse.2010.06.008.

[23] Rignot, E., Velicogna, I., van den Broeke, M. R., Monaghan, A. and Lenaerts, J., 2011. Acceleration of the contribution of 
the Greenland and Antartic ice sheets to sea level rise. Geophys. Res. Lett., 38, 5, L05503, doi: 10.1029/2011GL046583.

[24] Matsuo, K. and Heki, K., 2010. Time-variable ice loss in Asian high mountains from satellite gravimetry. Earth Planet. Sci. Lett., 290, 1-2, 30-36, doi: 10.1016/j.epsl.2009.11.053.

[25] Harig, C. and Simons, F. J., 2012. Mapping Greenland's mass loss in space and time. Proc. Natl. Acad. Sc., 109, 49, 1993419937, doi: 10.1073/pnas.1206785109.

[26] Simons, F. J., Dahlen, F. A. and Wieczorek, M. A., 2006. Spatiospectral concentration on a sphere. SIAM Rev., 48, 3, 504536, doi: $10.1137 /$ S0036144504445765.

[27] Harig, C. and Simons, F. J., 2015. Accelerated West Antarctic ice mass loss continues to outpace East Antarctic gains. Earth Planet. Sci. Lett., 415, 134-141, doi: 10.1016/j.epsl.2015.01.029.

[28] Tapley, B. D., Bettadpur, S., Ries, J. C., Thompson, P. F. and Watkins, M. M., 2004. GRACE measurements of mass variability in the Earth system. Science, 305, 5683, 503-505, doi: 10.1126/science.1099192.

[29] Riva, R. E. M., Bamber, J. L., Lavallée, D. A. and Wouters, B., 2010. Sea-level fingerprint of continental water and ice mass change from GRACE. Geophys. Res. Lett., 37, L19605, doi: 10.1029/2010GL044770.

[30] Bettadpur, S., 2007. Gravity Recovery And Climate Experiment Level-2 gravity field product user handbook. Technical report, Center for Space Research at The University of Texas at Austin.

[31] Swenson, S. and Wahr, J. M., 2006. Post-processing removal of correlated errors in GRACE data. Geophys. Res. Lett., 33, 8, L08402, doi: 10.1029/2005GL025285.

[32] Cheng, M., Tapley, B. D. and Ries, J. C., 2013. Deceleration in the Earth's oblateness. J. Geophys. Res., 118, 740-747. 10.1002/jgrb.50058.

[33] Bates, A. P., Khalid, Z. and Kennedy, R. A., 2017. Efficient computation of Slepian functions for arbitrary regions on the sphere. IEEE T. Signal Proces., 65, 16, 4379-4393, doi: 10.1109/TSP.2017.2712122.

[34] Paulson, A., Zhong, S. and Wahr, J., 2007. Inference of mantle viscosity from GRACE and relative sea level data. Geophys. J. Int., 171, 497-508. 10.1111/j.1365-246X.2007.03556.x.
[35] A. G., Wahr, J. and Zhong, S., 2013. Computations of the viscoelastic response of a 3-D compressible Earth to surface loading: an application to Glacial Isostatic Adjustment in Antarctica and Canada. Geophys. J. Int., 192, 557-572. $10.1093 /$ gji/ggs030.

[36] Harig, C. and Simons, F. J., 2016. Ice mass loss in Greenland, the Gulf of Alaska, and the Canadian Archipelago: Seasonal cycles and decadal trends. Geophys. Res. Lett., 43, 7, 3150-3159, doi: 10.1002/2016GL067759.

[37] Farinotti, D., Longuevergne, L., Moholdt, G., Duethmann, D., Mölg, T., Bolch, T., Vorogushyn, S. and Güntner, A., 2015. Substantial glacier mass loss in the Tien Shan over the past 50 years. Nature Geosci., 8, 716-722, doi: 10.1038/NGEO2513.

[38] Narama, C., Shimamura, Y., Nakayama, D. and Abdrakhmatov, K., 2006. Recent changes of glacier coverage in the western Terskey-Alatoo range, Kyrgyz Republic, using Corona and Landsat. Ann. Glaciol., 43, 223-229. 10.3189/172756406781812195.

[39] Jin, S., Tian, X. and Feng, G., 2016. Recent glacier changes in the Tien Shan observed by satellite gravity measurements. Global and Planetary Change, 143, 81-87. 10.1016/j.gloplacha.2016.06.006.

[40] Reager, J. T., Gardner, A. S., Famiglietti, J. S., Wiese, D. N., Eicker, A. and Lo, M.-H., 2016. A decade of sea level rise slowed by climate-driven hydrology. Science, 351, 6274, 699-703, doi: 10.1126/science.aad8386.

[41] Kääb, A., Berthier, E., Nuth, C., Gardelle, J. and Arnaud, Y., 2012. Contrasting patterns of early twenty-first-century glacier mass change in the Himalayas. Nature, 488, 7412, 495-498, doi: $10.1038 /$ nature11324.

[42] Bawa, K. S., Koh, L. P., Lee, T. M., Liu, J., Ramakrishnan, P. S., Yu, D. W., Zhang, Y. and Raven, P. H., 2010. China, India, and the environment. Science, 327, 5972, 1457-1459, doi: 10.1126/science.1185164.

[43] Yao, T., Pu, J., Lu, A., Wang, Y. and Yu, W., 2007. Recent glacial retreat and its impact on hydrological processes on the Tibetan Plateau, China, and surrounding regions. Arctic, Antarctic \& Alpine Res., 39, 4, 642-650.

[44] Huss, M., 2013. Density assumptions for converting geodetic glacier volume change to mass change. The Cryosphere, 7, 3, 877-887, doi: 10.5194/tc-7-877-2013.

[45] Harig, C., Lewis, K. W., Plattner, A. and Simons, F. J., 2015. A suite of software analyzes data on the sphere. Eos Trans. AGU, 96, 6, 18-22, doi: 10.1029/2015E0025851. 